\title{
The Effect of Ginger Water and Mint Leaves for Reduce Nausea and Vomiting in the 1st Trimester of Pregnancy
}

\author{
Yenita Agus $^{1 *}$, Rutfika Aiman Hidayat ${ }^{2}$ \\ \{ yenita.agus@uinjkt.ac.id ${ }^{1}$, rutfikaaiman@gmail.com ${ }^{2}$ \} \\ *corresponding author
}

Nursing Study Program, Faculty of Health Sciences, UIN Syarif Hidayatullah Jakarta, Pisangan Ciputat, 15412, Indonesia ${ }^{1,2}$

\begin{abstract}
Nausea and vomiting are common problem during pregnancy and the cause is unknown. To reduce symptom's, should intervene with the appropriate treatment. Some prefer to use herbal medicine instead of chemical agents. The study aimed was to determine the effectiveness of ginger water and mint leaves to reduce the frequency of vomiting in 1st trimester of pregnancy. This was a quasi - experimental study using pretest and posttest group. The samples were 32 the 1 st trimester of pregnant women who experience nausea and vomiting, which were taken using purposive sampling technique. Data collection used demographic sheets and PUQE-24 index to determine the nausea and vomiting for a week using form pre-test and post-test. There are significant differences between pre- and post- intervention (mean 8.25; 5.50) with $p$ value 0.000 . Giving Ginger water and mint leaves may be an effective treatment for reducing nausea and vomiting in pregnancy.
\end{abstract}

Keywords: Ginger and mint leaves, nausea and vomiting, 1st trimester

\section{Introduction}

Pregnancy is a period of transition with important physiological, psychological and emotional changes, which can be challenging and stressful for the women [1], [2]. Even in uncomplicated pregnancies, these changes can affect the quality of life of pregnant women and affect both maternal and infant health. Most pregnant women experience pregnancy-related conditions, of which nausea and vomiting during pregnancy (NVP) is by far one of the most common.

More than $90 \%$ of pregnant women will experience nausea and vomiting of varying severity and generally symptoms emerge starting 4-9 weeks of gestation [3]. About 20-30\% of pregnant women will experience symptoms beyond 20 weeks, up to time of delivery and around $2 \%$ of women will develop hyperemesis gravidarum (HG) [4] (Linseth, 2005). Hyperemesis gravidarum is a syndrome triggered by the placenta with the final phenotype arising from different pathway [5].

Many causes, such as hormonal, immunological and psychological, are contributors to nausea and vomiting during pregnancy, although inconsistently in many studies. However, the etiology of nausea and vomiting remains unknown. Some risk factors are recognized as causes of hyperemesis gravidarum such as hyperthyroid disorders, preexisting diabetes, psychiatric illnesses, and gastrointestinal disorders [5]. Even though, nausea and vomiting, including 
hyperemesis gravidarum, do not appear to have an adverse effect on the outcome of pregnancy or the baby's health as long as the mother can keep hydrated; the treatment depends on how severe the symptoms are. About nearly $2 \%$ of pregnancy has experiences with severe nausea and vomiting, which can lead to dehydration, electrolyte disturbances, damage of the developing fetus and damage of the liver [6].

Many medications are currently available for reducing of nausea and vomiting during pregnancy. For most women, nausea and vomiting is an accepted part of pregnancy and no further treatment is needed for these women [5]. Pharmacological treatments used in many cases, however, raise concerns about the effect of drugs administered during the critical embryonocs pregnancy, drastically limiting their use. Avoiding the effect of drugs administered, women used the nonpharmacological approaches to solve their problem. Complementary therapies these include diet, acupressure and acupuncture and natural drugs are chamomile, peppermint and raspberry leaf and ginger reports the commonly used by the women [7].

Ginger (zingiber officinale) has been widely used as a spice to enhance the flavor of food and for medical purposes, particularly to treat ailments such as diarrhea, stomachache and nausea [8]. Study for 70 women using $1 \mathrm{gr} / \mathrm{day}$ of ginger compared to $40 \mathrm{mg} / \mathrm{day}$ of pyridoxine recommend that ginger significantly relieving nausea [9]. In addition, traditionally, peppermint or Menta Pepperita also has been used to treat antispasmodic, analgesic, antidepressant and nausea and vomiting; a perennial, aromatic, medicinal herb used in traditional medicine [10]. Menthol is the main component of peppermint and generally peppermint contains $1.2 \%-1.5 \%$ volatile oils, comprising $30 \%-70 \%$ menthol and menthol esters and more than 40 other ingredients such as flavonoids (12\%), polymerized polyphenols (19\%), carotene, tocopherol, and beta-thioculin[11,12].

Considering of the effect of nausea and vomiting during the pregnancy, alternative therapies can be used for the women. The treatment given based on the range of severity, for most women, nausea and vomiting is an accepted part of pregnancy, however, it is important to recognize the risk possible of affected women. Then, the purpose of this study was to know effect of ginger water combined with mint leaves to reduce frequency of nausea and vomiting during the 1 st trimester of pregnancy.

\section{Methods}

\section{Research design}

This was a Quasy Experiment with two group pretest-postest research design was conducted to evaluate the effect of ginger water and mint leaves to reduces the nausea and vomiting during 1 st trimester of pregnancy.

\section{Samples}

This study was performed on 32 women in 1st trimester of pregnancy. Study conducted in Cisauk, Bogor, Indonesia during April to June 2019. The women were randomly allocated 
to treatment two experimental groups. The treatment group received (ginger and mint leaves) and control group using mint leaves.

\section{Study population}

We used purposive sampling technique to recruit women who were advised to use ginger and mint leaves for the management to reduce nausea and vomiting during pregnancy. Personal contact (post integrated person) in the field helped identifying and recruiting the potential women who agreed to take part in the study. Informed consents were taken from all women before participation on this study. The Inclusion criteria were as follow: 1) does not experience pregnancy complications, 2) does not experience gastroenteritis, 3) does not have allergies to ginger and mint leaves, 4) does not take anti-nausea drugs, 5) willingness to be a respondent and was recommended to use ginger and mint leaves.

Exclusion criteria: 1) Women who have pregnancy complication such as hypertension, diabetes, had gastrointestinal disorders, 2) taking therapeutic doses of antiemetic, 3) women who had allergy to ginger and peppermint.

\section{Instruments}

The data collection used was the observation sheet and the Pregnancy-Unique Quantification Index of Emesis Nausea (PUQE) -24[13] to determine the frequency of nausea and vomiting which was assisted by researchers to fill in for a week in the form of pre-test and post-test.

PUQE-24 is a delivery system for measuring the severity of nausea and vomiting within 24 hours. The PUQE score for each patient was calculated using three criteria to assess the severity of nausea and vomiting during pregnancy, the number of vomiting episodes, and the number of episodes of dry vomiting and eating sounds in the throat in the past 24 hours. The PUQE score is calculated by adding the values of each criterion, and can range from a minimum of 1 to a maximum of 15 .

Regimens

A. Intervention group (ginger and mint leaves boiled) was given for 5 days, starting from the day 2 to day 6 . The ingredients are Ginger 2.5 gram and mint leaves 3-5 slices, brown sugar 10 gram and mineral water $250 \mathrm{cc}$. All ingredients are boiled together and drink it on one time.and boiled them and drink it on one time.

B. Control group (mint leaves) was given for 5 days, starting from the day 2 to day 6 . The ingredients are mint leaves 3-5 slices and brown sugar 10 gram and mineral water 250 gram. All ingredients are boiled together and drink it on one time.

\section{Procedure}

We distribute the questionnaire to the women who are in 1st trimester of pregnancy in the clinic who had recruited women meeting the eligibility criteria. The data obtained came from the nausea and vomiting assessment sheet (PUQE) which was filled out by the researchers through a pre-test with pregnant women in the 1st trimester who experienced 
nausea and vomiting. Data were collected twice, namely, the day before the treatment and the day after the treatment was carried out within the specified time.

\section{Ethical consideration}

This study was approved by Ethics Committee of Faculty of Health Sciences Syarif Hidayatullah State Islamic University. Thirty-two women participated on this study (16 treatment groups and 16 women control group). The BPM Yuliana Clinic provided permission to conduct the study in their clinic. Informed consent to participate in the study was sought from the respondent with confidentiality assured when conducting the study.

\section{Data analysis}

Descriptive data were used to describe the characteristics of the women covers age, background education, working, gravida and gestational age. The ginger water and mint leaves effects were compared using the average score in the pretest and posttest in each group (intervention and control group) using Wilcoxon analysis which level of significant 0.005 bilateral. Statistical analysis software: SPSS ver. 19 for windows).

\section{Results}

In this study, a total 32 women were recruited to participate. Therefore, the women were divided into two groups. The treatment group used ginger and mint leaves water and the other group used mint leaves only.

Table1. Characteristics of the women

\begin{tabular}{|c|c|c|c|c|c|}
\hline \multirow{3}{*}{ Variables } & & \multicolumn{2}{|c|}{ Ginger and Mint Leaves } & \multicolumn{2}{|c|}{ Mint leaves } \\
\hline & & \multicolumn{2}{|c|}{$(\mathrm{N}=16)$} & \multicolumn{2}{|c|}{$(\mathrm{N}=16)$} \\
\hline & & $\mathrm{N}$ & $\%$ & $\mathrm{~N}$ & $\%$ \\
\hline \multicolumn{6}{|l|}{ Age } \\
\hline & $20-35$ years & 13 & $(81.3)$ & 14,0 & 87.5 \\
\hline & $\begin{array}{l}35 \text { years or } \\
\text { more }\end{array}$ & 3 & $(18.7)$ & 2,0 & 12.5 \\
\hline \multicolumn{6}{|c|}{ Background education } \\
\hline & $\begin{array}{l}\text { Elementary } \\
\text { School }\end{array}$ & 2 & 12,5 & 2 & 12.5 \\
\hline & $\begin{array}{l}\text { Junior High } \\
\text { School }\end{array}$ & 1 & 6,2 & 2 & 12.5 \\
\hline & $\begin{array}{l}\text { Senior high } \\
\text { school }\end{array}$ & 9 & 56,2 & 10 & 62.5 \\
\hline & $\begin{array}{l}\text { Diploma/Uni } \\
\text { versity }\end{array}$ & 4 & 25 & 2 & 12.5 \\
\hline \multicolumn{6}{|l|}{ Working } \\
\hline & No work & 9 & 56,2 & 9 & 56.2 \\
\hline
\end{tabular}




$\begin{array}{lcccc}\text { Government } & 1 & 6,2 & 1 & 6.2 \\ \text { Farmer } & 4 & 25 & 5 & 31.2 \\ \text { Labour } & 2 & 12,5 & 1 & 6.2\end{array}$

Gravida

$\begin{array}{lcccc}\text { Primigravida } & 11 & 68,8 & 9 & 56.2 \\ \text { Multigravida } & 5 & 32.2 & 7,0 & 43.8\end{array}$

Gestational age

$\begin{array}{lcccc}0-6 \text { weeks } & 5 & 31,2 & 4 & 25 \\ 7-12 \text { weeks } & 11 & 68,8 & 12 & 75\end{array}$

The majority of the overall sample (treatment group) was 25-35 years old 13 women $(81.3 \%)$. The majority (56.2\%) had completed twelve years of basic education and $56.2 \%$ were not employed. In addition, most of the women were primiparous $11(68.8 \%)$ and $68.8 \%$ in 7 12 weeks of pregnancy. In the control group, the characteristics of the women did not significantly differ from the treatment group while $87.5 \%$ was under 35 years old and $62.5 \%$ completed the twelve years basic education and did not work $9(56.2 \%)$. Therefore, majority of the women were primiparous and gestational aged of the women are 7-12 weeks of pregnancy. Details are given in Table 1.

Table2. Effects of the group using the ginger combined mint leaves and mint leaves

\begin{tabular}{|c|c|c|c|c|c|}
\hline Component & Variable & Mean & SD & Min-Max & p-Value \\
\hline \multirow[t]{2}{*}{$\begin{array}{l}\text { Ginger and } \\
\text { mint leaves }\end{array}$} & $\begin{array}{l}\text { Frequency of } \\
\text { nausea and } \\
\text { vomiting } \\
\text { before } \\
\text { intervention }\end{array}$ & 8.25 & 0,479 & $6-12$ & 0.000 \\
\hline & $\begin{array}{l}\text { Frequency of } \\
\text { nausea and } \\
\text { vomiting after } \\
\text { intervention }\end{array}$ & 5.5 & 0,479 & $3-9$ & \\
\hline \multirow[t]{2}{*}{ Mint leaves } & $\begin{array}{l}\text { Frequency of } \\
\text { nausea and } \\
\text { vomiting } \\
\text { before } \\
\text { intervention }\end{array}$ & 9.06 & 0.479 & $5-12$ & 0.002 \\
\hline & $\begin{array}{l}\text { Frequency of } \\
\text { nausea and } \\
\text { vomiting after } \\
\text { intervention }\end{array}$ & 8.12 & 0.512 & $5-11$ & \\
\hline
\end{tabular}

Table 2 describes the scores of women who take ginger water and mint leaves and were given mint leaves before and after the program (Intervention group). the frequency of the nausea and vomiting decreased after the intervention within a week of treatment with standard deviation 0.479 with frequency of nausea and vomiting ranged 6-12 in pre-test group and ranged 3-9 times in post-test group. The mean of the women who were given ginger water and 
mint leaves pre-test was 8.25 and 5.5 in the post-test, which was a significant decrease ( $p=$ $0.000)$. In addition, the ranged of nausea and vomiting was 5-12 times $(\mathrm{SD}=) 0.479)$ in the pretest and 5-11 in the post test with standard deviation 8.12. However, in control group scores pretest was 9.06 and 8.12 in the post-test which showed statistically significant between pretest and post- test $(p=0.002)$.

\section{Discussion}

In this study majority of both samples are age ranged 25-35 years old. We used the purposive sampling technique to recruit the women to participate. Using these sampling techniques, we recruited women who were not employed, completed twelve years of basic education, primiparous women and women in 7-12 weeks of pregnancy are the majority.

In this present study, all groups were effective for reducing the nausea and vomiting during in the 1st trimester of pregnancy. However, mixed ginger and mint leaves were more effective than the control group (mint leaves). Some study also found some result with our study. Study from Iran found that ginger decrease frequency of nausea and vomiting after caesarian section [14]. In addition, Sharifzadeh[15] study divided women into three groups as follows, placebo group, vitamin B6 group and ginger group, and this comparison showed that ginger was more effective than other group.

Some studies for the other researchers found the same result, the third double blind RCT included 23 pregnant women in the 1st trimester of pregnancy, after 9 days of treatment, and nausea levels were reduced in $77 \%$ and $20 \%$ of women in the ginger and placebo groups [16]. On contrary study form Iran indicated that ginger and chamomile are ineffective on decreasing the frequency of pregnancy [17].

Nausea and vomiting in the 1st trimester of pregnancy is very common and some women do not need some treatments and accept as an apart of pregnancy. Nausea and vomiting is a major deterrent of well-being for many women and will be impact to their pregnancy experience. Many of the women feel their condition is normal during pregnancy and do not need to seek the health care provider. Improving women's awareness, that women should seek the health care provider during the pregnancy especially with troublesome symptoms which affect their comfort, is needed. Effective treatment should be made available to the women, either medical or alternative therapy.

\section{Conclusions}

Nausea and vomiting during pregnancy have marked negative impacts on many women's experiences. Health care providers should recognize nausea and vomiting as a problem and should give them the appropriate treatment even when symptoms are moderate. Providing the appropriate treatment can improve the health of the-baby and mother. Ginger and mint leaves may be a safe treatment of nausea and vomiting. Addressing important benefits of using ginger and mint leaves for the management of nausea and vomiting during the 1st 
trimester of pregnancy and reducing duration of the nausea and vomiting is important. The health care provider should recommend this treatment as a solution for the women who have symptoms. Further studies are still needed to conduct on the different doses of ginger and mint leaves to identify the ideal doses and compare that effect with the characteristic of the women such as age, pregnancy experience and gestational age.

In conclusion, the study found that both group ginger and mint leave (treatment group) and mint leaves (control group) reduce nausea and vomiting during the 1st trimester of pregnancy. It can be concluded that ginger is easy to get, cheap and easy to drink and safe to use.

\section{Acknowledgements}

This study is based on the bachelor essay by Ruftika. We would like to express our appreciation to all the dear participants and the BPM Yuliana to permit us to conduct our study in their clinics. We also thank Syarif Hidayatullah State Islamic University for allowing us to conduct the study.

\section{References}

[1] BarclayL, EverittL, RoganF, SchmiedV,Wyllie A.Becoming a mother-Ananalysis of women's experience of early motherhood. Journal of Advanced Nursing.1997;25(4):719-28.PMID:91046673

[2] Nystrom. K, Ohrling K. Parenthood experiences during the child's first year: Literature review;46(3):319-30( 2004). https://doi.org/10.1111/j.13652648.2004.02991.xPMID:150661134

[3] Einarson, A., Maltepe. C., Boskowic. R., Koren.G ; Treatment of Nausea and Vomiting in Pregnancy: an updated algorithtm. Can Farm Physician. 53(12): 2109-2111 (2007).

[4] Linseth.G., Van.P: Nausea and Vomiting in late Pregnancy. Health Care Human International. 26(5).372-386 (2005).

[5] Tan. C. P., Omar. Z.S : Contemporary Approaches to Hyperemesis During Pregnancy.

[6] Ebrahimi, N., Maltepe, C., Einarson, A: Optimal management of nausea and vomiting of pregnancy. International Journal of Women's Health. Pp241-248 (2010)

[7] Borreli, F., Capasso. R., Aviello, G., et.al: Effectiveness and Safety of Ginger in the Treatment of Pregnancy-Induces Nausea and Vomiting. American College of Obstetricians and Gynecologists. Vol.105 No.4 (2015).

[8] White.B.: Ginger and Overview. Am Farm Physician. 75(11): 1689-1691 (2007).

[9] Ensiyeh.J., Sakinah.M.A: Comparing Ginger and Vitamin B6 for the Treatment of Nausea and Vomiting in Pregnancy of Randomized Control Trials. Midwifery. 25.64953 (2009).

[10] N. Beheshti-Poor, N. Jamali Moghadam, S. Soleimani, A. Haghnegahdar, A. Salehi, Assessment of knowledge, belief and function of people about herbal medicines who 
referred to one of clinics dependent to medical university of Shiraz in 2010, J. Herb. Drugs (An International Journal on Medicinal Herbs) 1 (4) 53-59 (2011).

[11] Gardiner, P. Peppermint (mentha piperita). The Center for Holistic Education and Research 2 1-22. Revised May (2000).

[12] Yazdani,D., A. Jamshidi, F. Mojab, Comparison on menthol content of cultivated peppermint at different regions of Iran, J. Med. Plants 3 (3) (2002) 73-77.

[13] Ebrahimi, N., Maltepe, C., Bournissen, F. ., \& Koren, G. (2009). Optimal management of nausea and vomiting of pregnancy: Using the 24-hour Pregnancy-Unique Quantification of Emesis (PUQE-24) Scale. J Obstet Gynaecol Can. 803-807. Retrieved from http://www.jogc.com/abstracts/full/200909_Obstetrics_4.pdf

[14] Pakniat, H., Lalooha,F., Movahed, F., et.al: The effect of ginger and metoclopramide in the prevention of nausea and vomiting during and after surgery in cssarean section under spinal anesthesia. Obstetric \& Gynecology Science. 6(2) pp 173-180 (2020)

[15] Sharifzadeh.F., Kashanian.M., Koupayehzadeh., et.al: A Comparison between the effect of ginger, pirodoxine (Vitamin B6) and Placebo fot the Treatment of the 1st trimester Nausea and Vomiting Pregnancy (NVP). The Journal of Maternal-Fetal and Neonatal Medicine. 1476-4954 (2017).

[16] Guleser.G.N., Tasci. S., Kaplan B: The experience of Sympthoms and information need of cancer patients undergoing radiotherapy. Jurnal cancer Education 27:46-53 (2012)

[17] Sanaati, f., Najah,S., Kashaninia,S., Sadeghi.M: effect of Ginger and Chamomile on Nausea and Vomiting Caused by Chemotheraphy in Iranian Women with Breast Cancer. Asian Pacific Journal of Cancer Prevention. Vol.17 (2016) 